\title{
A content analysis of Australian television advertising: focus on child and adolescent oral health
}

\author{
Amit Arora ${ }^{1,2,3,4^{*}}$, Caroline M. Bowman ${ }^{5}$, Stephanie J. P. Chow ${ }^{5}$, Jack Thepsourinthone ${ }^{1}$, Sameer Bhole $e^{4,5}$
} and Narendar Manohar ${ }^{1}$

\begin{abstract}
Background: Children's preferences for cariogenic foods and/or drinks has been proven to be associated with exposure to advertisements. This study aimed to assess and compare the proportion of cariogenic food and /or drink advertisements aired on three metropolitan Sydney commercial television channels at different broadcast times during school term and school holidays.

Methods: Three Sydney free-to-air television channels (Channels Seven, Nine, and Ten) were recorded between June 2016 and January 2017. Two weekdays and one weekend day were recorded for a week for each channel during the school term and school holidays, respectively. All channels were recorded from $0630 \mathrm{~h}$ until $2300 \mathrm{~h}$. Food and/or drink advertisements were categorised according to the time they were aired and their sugar and acid content. For each channel, school holiday data was compared with school term data. Pearson chi-squared testing was used to determine the difference in advertisements rates across TV channels and broadcast times including school holidays and school term.

Results: The proportion of food and/or drink advertisements for all networks was less than 10\% of all advertisements. Overall, Channel Ten had the most food and/or drink advertisements (39.74\%) and Channel Seven had the lowest (28.60\%). Channel Ten aired the largest proportion of food and/or drink advertisements (27.18\%) during school term Channel Nine aired the highest number of food and/or drink adverts (15.50\%) during school holidays. There were more food and/or drink advertisements during children's viewing hours compared to overlap, adult, and other viewing periods respectively, with Channel Ten airing the highest advertisements (15.72\%) and Channel Seven airing the least (11.35\%) food and/or drink advertisements. For all analyses, Pearson chi-square tests had a $p$-value $<0.001$.

Conclusion: Although the overall proportion of food and/or drink advertisements aired on Sydney television is low, the advertisements containing high sugar and /or acid were broadcasted more during children's viewing times than other times and during school term compared to school holidays.
\end{abstract}

Keywords: Dental caries, Television advertisement, Australia, Cariogenic, Content analysis

\footnotetext{
* Correspondence: a.arora@westernsydney.edu.au

${ }^{1}$ School of Science and Health, Western Sydney University, Campbelltown

Campus, Locked Bag 1797, Penrith, NSW 2751, Australia

${ }^{2}$ Translational Health Research Institute, Western Sydney University,

Campbelltown Campus, Locked Bag 1797, Penrith, NSW 2751, Australia

Full list of author information is available at the end of the article
}

(c) The Author(s). 2018 Open Access This article is distributed under the terms of the Creative Commons Attribution 4.0 International License (http://creativecommons.org/licenses/by/4.0/) which permits unrestricted use, distribution, and reproduction in any medium, provided you give appropriate credit to the original author(s) and the source, provide a link to the Creative Commons license, and indicate if changes were made. The Creative Commons Public Domain Dedication waiver (http://creativecommons.org/publicdomain/zero/1.0/) applies to the data made available in this article, unless otherwise stated. 


\section{Background}

Dental caries (tooth decay) is recognised as a global public health concern by the World Health Organization (WHO) [1]. The Global Burden of Disease 2015 Study [2] reports that nearly 573 million children are affected by untreated dental caries in primary (baby) teeth. Further, untreated caries in permanent (adult) teeth was the most prevalent condition in all of GBD 2015 affecting 2.5 billion people worldwide [2]. In Australia, recent evidence shows that caries rates in the primary dentition has been increasing since 1995 [3] and is considered to be a strong predictor of caries in the permanent dentition [4] and has the potential to produce significant costs to the health sector [5]. Where hospitalisation is necessary, management of this entirely preventable disease is estimated to directly cost US\$3300 (over \$4000 AUD) per case without accounting for the social and economic costs to the family [5]. Although dental caries is a multifactorial disease [6], detrimental changes in diet, in particular, increased frequency of snacking on sweet foods and increased consumption of sugar sweetened beverages have been majorly attributed to the rise in caries incidence [7-10].

The consumption of cariogenic foods is influenced by children's television advertising and marketing [11]. Children's preferences for foods and drinks has been proven to be associated with exposure to television advertisements [12-15]. Previous observational research has noted that high levels of television viewing are associated with greater consumption of energy-dense, nutrient-poor food and drinks [13-17]. More recent evidence, however; suggests it may be the advertising, rather than the television viewing per se, that is particularly detrimental [18]. The use of persuasive marketing techniques such as employing celebrities, cartoon characters, athletes, and promotional gifts associated with advertising are commonly used in the marketing of unhealthy/non-core foods and drinks for children $[19,20]$. Such persuasive marketing is proven to promote brand recognition, food preferences, purchase requests and food consumption in children [13-15].

Internationally, there is a dearth of evidence on television advertising and oral health. A study by Sukumaran et al. [21] analysed the content of advertisements in India and reported that $55.6 \%$ adverts were on food, of which $46.8 \%$ focused on sugar-rich foods. On the other hand, Al-Mazyad et al. [22] reported that nearly two-thirds of the food adverts in UK were for items potentially harmful to oral health. Another study by Morgan and colleagues [23] in the UK reported that $16.4 \%$ of the advertisements time was devoted to food products, and $6.3 \%$ of all advertising time to potentially cariogenic products. Rodd and Patel [24] also reported that $34.8 \%$ adverts on UK television were related to food and drinks, of which $95.3 \%$ were for food and drinks high in sugar and/or acid. A recent systematic review and a meta-analysis [25] that assessed the content of television advertising in terms of oral health concluded that $38 \%$ of the advertisements were related to food and of those, $70.6 \%$ were related to cariogenic foods in particular. Although the meta-analysis is recent [25], some international literature was not included in the meta-analysis [23, 26], and that to the best our knowledge there seems to be no Australian research on television advertising and oral health.

In Australia, the current system of regulating food advertising aimed at children comprises of both mandatory and self-regulatory elements. The mandatory element is embedded in Children's Television Standards, which cover television viewing times for children, and is regulated by the Australian Communications and Media Authority [27]. The mandatory Children's Television Standards does not restrict the promotion of advertisements in general; however, they do restrict promotions involving celebrities for children's programs [27]. Therefore, it is recommended that food advertisements should be restricted before, during, and after, all the television programs aimed specifically for children [28, 29]. Furthermore, two self-regulatory codes, Responsible Children's Marketing Initiative [30] and the Australian Quick Service Restaurant Industry Initiative [31], have been introduced in Australia, aimed at reducing children's exposure to advertisements promoting unhealthy foods and drinks. Despite these mandatory and self-regulatory guidelines, a review of the literature has shown that unhealthy foods and drink items are still often advertised on local television [32-36].

Content analyses of children's food advertising focusing on unhealthy/non-core foods have concluded that, despite regulatory changes, Australian children continue to see a large amount of advertising for non-core foods [28, 29, 32-36]. This is concerning given that the 2011-12 Australian Health Survey highlighted that children and young people (5-17 years) spent almost $136 \mathrm{~min}$ per day in sedentary activities such as television viewing [37]. Although there is some research on Australian television advertising in relation to obesity [28, 29, 32-36], there is paucity of data about television advertisements related to oral health [38]. This research addresses this gap by examining the content of television advertising across three most common free-to-air Sydney channels with respect to oral health.

The aims of this study are:

1. To examine the distribution and content of television advertising across three metropolitan Sydney free-to-air channels with a specific reference to oral health.

2. To compare the proportion of food and/or drink advertisements aired on three metropolitan Sydney free-to-air television channels during school holidays and school term, respectively, with a focus on oral health. 
3. To compare the proportion of food and/or drink advertisements aired on three metropolitan Sydney free-to-air television channels based on the broadcast time with a focus on oral health.

\section{Methods}

Three most commonly viewed free-to-air Sydney television channels (Channels Seven, Nine, and Ten) were recorded between May 2016 and October 2016. A total of 6 days i.e., two weekdays and one weekend day, during school term and school holidays respectively. The channels and days were selected based on television ratings data obtained from OzTAM (Australian Television Audience Measurement) (available at http://www.oztam.com.au) and based on prior Australian research [32, 39]. Public holidays and days having large scale sporting events were excluded to ensure that the data represented typical and/or routine broadcasting. All channels were recorded from $0630 \mathrm{~h}$ until $2300 \mathrm{~h}$. The advertisements of all the three selected channels were recorded simultaneously onto the hard-discs or DVD's.

\section{Coding}

All advertisements were viewed and analysed by three researchers $(\mathrm{SC}, \mathrm{CB}$, and $\mathrm{AA})$. Advertisements were initially categorised as "food and/or drink advertisements" or "non-food and/or drink advertisements". Subsequently, the "food and/or drink advertisements" were sub-categorised based on two main criteria:

1. Broadcast time: Broadcast time was divided into four categories. Table 1 shows the time periods of each broadcast time:

- Peak child-viewing time, also known as $\mathrm{C}$ band time-period (as defined in Children's Television Standards [27]).

- Peak adult-viewing time (determined as per Australian television networks [40])

Table 1 Summary of time periods/brackets for weekdays and weekends during School Term and School Holidays

\begin{tabular}{llllll}
\hline \multirow{2}{*}{ Broadcast time } & \multicolumn{2}{l}{ School Term } & & \multicolumn{2}{l}{ School Holiday } \\
\cline { 2 - 3 } Child & Weekdays & Weekend & & Weekdays & Weekend \\
Adult/prime time & $20700-0830$ & $0700-2030$ & & $0700-2030$ & $0700-2030$ \\
Overlap & $1600-2030$ & & & & \\
Other & $1800-2030$ & $1800-2300$ & & $2030-2300$ & $1800-2300$ \\
& $0630-0700$ & $0630-0700$ & & $0630-0700$ & $0630-0700$ \\
& $0830-1600$ & & & & \\
\hline
\end{tabular}

- Overlap time-period (between $1600 \mathrm{~h}$ and $2030 \mathrm{~h}$ when children watch television under adult supervision).

- Other time period

2. Food and/or drink type: These categories are based on sugar and acid content of the food and/or drink as described by Rodd and Patel [24]. The categories are:

- Group 1 represents foods and/or drinks high in sugar, such as confectionery (sweets, biscuits, cakes), breakfast cereals with added sugar, breakfast bar and flavoured milk products.

- Group 2 represents foods and/or drinks with high acid content, such as sugar-free soft drinks.

- Group 3 represents foods and/or drinks with high sugar and acid content, including soft drinks (carbonated and non-carbonated).

- Group 4 represents foods and/or drinks with low sugar and low acid content. This includes dairy products, breakfast cereals with no added sugar, tea/ coffee and convenience food.

Only those advertisements which were aired during the in-between breaks of televised programs were considered for the study purpose, whereas 'infomercials' during the televised programs or advertisement banners displayed at the corner of televised programs were not included. Duration of advertisements or frequency of specific adverts were not recorded. Adverts with multiple products (e.g., weight loss programs) in which food and/or drink was just one of the advertised products, were classified as "non-food and/or drink" advertisements, since they were not designed to actively promote a specific food and/or drink product. Additionally, advertisements promoting alcohol were classified as "non-food and drink advertisement" since they were not targeted towards children.

\section{Statistical analysis}

Statistical Package for Social Science (SPSS) version 22 (SPSS for Windows, SPSS Inc., Chicago, IL, USA) was used for data management and analysis. Data were analysed descriptively to determine the proportion of food and/or drink advertisements according to sugar and acid content and viewing time-periods across each TV channel. Additionally, using a Bonferonni adjusted $\alpha$ of 0.01 , a series of one-way chi-square analyses were conducted to compare the proportion of advertisements across TV channels; 
during school term and school holidays, and during peak child, overlap, adult, and other viewing times, respectively.

\section{Results}

A total of $297 \mathrm{~h}$ of television programs including advertisements was recorded. There were 12,121 advertisements aired during the 6 days of recording. Food and/or drink advertisements as a proportion of all advertisements aired during the six-day study period was less than $10 \%$ for all TV networks. Of all advertisements, 916 (7.56\%) were of food and/or drinks while 11,205 (92.44\%) advertisements were non-food and/or drink related. Figure 1 shows the distribution of advertisements across the four food and/or drink categories. Of the 916 food and/or drink advertisements, 5.02\% were for high sugar and high acid foods and/or drinks, 35.15\% were for high sugar foods and/or drinks, $57.96 \%$ for foods and/or drinks that were low in both sugar and acid, while 1.86\% were for food and/or drink items high in acid content only. The one-way chi-square test revealed a significant difference in the proportion of advertisements across the four food and/or drink categories, $X^{2}=778.54, p<.001$.

Table 2 shows the distribution of food and/or drink advertisements across all networks. A significant difference in the number of food and/or drink adverts across all recorded networks was observed, $X^{2}=18.19, p<.001$. Overall, Channel Ten aired the highest number $(n=364)$ of food and/or drink advertisements over the six-day study period while Channel Seven aired the lowest number $(n=262)$ of food and/or drink adverts.

Table 3 shows the percentage of food and/or drink advertisements (sub-categorised into four food and/or drink groups) across all three channels according to whether they were aired during school term or school holidays. Channel Ten aired the largest proportion of food and/or drink advertisements $(n=249)$ during school term Channel Nine aired the highest number of food and/or drink adverts $(n=142)$ during school holidays. Overall, Channel Seven aired the lowest percentage of food and/or drink related advertisements during both school term $(n=147)$ and school holidays $(n=115)$. A one-way chi-square revealed a statistically significant difference between the proportion of food and/or drink adverts during school term and school holidays, $X^{2}=32.30$, $p<.001$, whereby food and/or drink advertisements were more frequently aired during the school term.

Table 4 shows the percentage of food and/or drink advertisements (sub-categorised into four food and/or drink groups) across all three channels according to the broadcast time i.e. whether they were aired during peak child, overlap, adult, and other viewing periods. When comparing the proportion of overall food and/or drink advertisements distributed across child, adult, overlap, and other viewing periods; it was revealed that there is a wide range of distribution i.e., from a minimum value of $3.49 \%$ to a maximum value of $15.72 \%$. A statistically significant difference was found between the proportion of food and/or drink adverts aired during the four specified viewing periods, $X^{2}=118.75, p<.001$ irrespective of the TV networks. Foods and/or drinks were advertised more frequently during the peak child-viewing period $(n=$ $359)$ compared to the overlap $(n=216)$, adult $(n=211)$, and other $(n=130)$ viewing periods. Furthermore, a statistically significant difference was revealed between the proportion of food and/or drink adverts on the three broadcast channels across other viewing times $\left(X^{2}=\right.$ 13.49, $p<.001$ ), respectively. Channel Ten had the highest proportion of food and/or drink advertisements during child $(n=144)$, overlap $(n=83)$, adult $(n=74)$, and other viewing periods $(n=63,6.48 \%)$. Conversely, Channel Seven had the lowest proportion of food and/or drink advertisements for child $(n=104)$, overlap $(n=57)$, adult $(n=66)$, but not other viewing periods $(n=35)$.

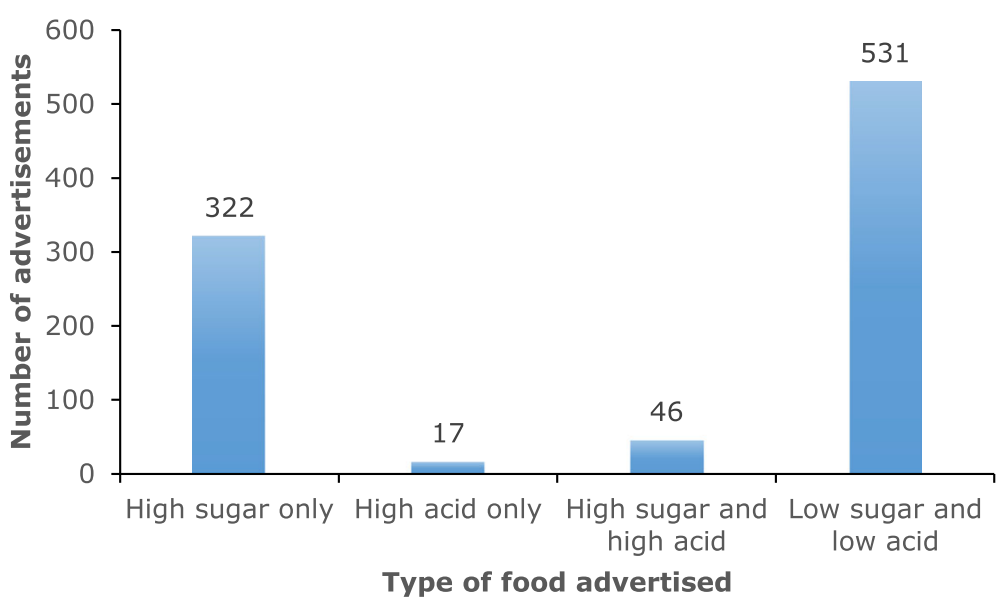

Type of food advertised

Fig. 1 Distribution of cariogenic food and/or drinks advertisements categorised according to nutritional content 
Table 2 Distribution of food and/or drink advertisements according to broadcast channels

\begin{tabular}{|c|c|c|c|c|c|c|}
\hline \multirow[t]{2}{*}{ Television Channel } & \multicolumn{2}{|c|}{ Seven } & \multicolumn{2}{|l|}{ Nine } & \multicolumn{2}{|l|}{ Ten } \\
\hline & $n$ & (\%) & $n$ & (\%) & $n$ & (\%) \\
\hline High Sugar Group & 97 & 10.59 & 95 & 10.37 & 130 & 14.19 \\
\hline Breakfast cereals with added sugar & 7 & 0.76 & 6 & 0.66 & 10 & 1.09 \\
\hline Confectionery (sweets, biscuits, cakes) and snacks & 85 & 9.28 & 74 & 8.08 & 112 & 12.23 \\
\hline Flavoured milk drinks & 5 & 0.55 & 15 & 1.64 & 8 & 0.87 \\
\hline High acid group & 7 & 0.76 & 1 & 0.11 & 9 & 0.98 \\
\hline Sugar-free soft drinks and fruit juices & 7 & 0.76 & 1 & 0.11 & 9 & 0.98 \\
\hline High sugar and high acid group & 17 & 1.86 & 10 & 1.09 & 19 & 2.07 \\
\hline Sugar-sweetened drinks & 17 & 1.86 & 10 & 1.09 & 19 & 2.07 \\
\hline Low sugar and low acid group & 141 & 15.39 & 184 & 20.09 & 206 & 22.49 \\
\hline Dairy products & 13 & 1.42 & 8 & 0.87 & 10 & 1.09 \\
\hline Breakfast cereals with no added sugar & 5 & 0.55 & 11 & 1.20 & 14 & 1.53 \\
\hline Tea/coffee & 16 & 1.75 & 4 & 0.44 & 13 & 1.42 \\
\hline Convenience foods & 107 & 11.68 & 161 & 17.58 & 169 & 18.45 \\
\hline Total food advertisements & 262 & 28.60 & 290 & 31.66 & 364 & 39.74 \\
\hline
\end{tabular}

${ }^{*}$ Chi-square $\left(X^{2}\right)=18.19, p<.001$

\section{Discussion}

To the best of our knowledge, the present study seems to be the first Australian research related to content analysis on television advertisements with a focus on oral health. Specifically, the food and/or drink advertisements were studied for specific peak viewing periods across three networks during the school term and school holidays in metropolitan Sydney. The proportion of food and/or drink advertisements for all networks was less than $10 \%$ of overall televised transmission time. Channel Ten had the most food and/or drink advertisements and Channel Seven had the lowest proportion of food and/or drink adverts. This proportion is considerably less than that reported by Kelly et al. (25.5\%) [19], Rodd and Patel (34.8\%) [24], and Hebden et al. (28\%) [35] in their respective studies. The Australian study by Hebden et al. [35] reported data for channels specifically targeting children $<12$ years, different times of the day (7.00 until 20.30), and different time of the year (February 2009) which may account for differences in findings. Likewise, another Australian study by Kelly and colleagues [32]

Table 3 Distribution (\%) of food advertisements according to school term (ST) and school holiday (SH) broadcast periods ${ }^{*}$

\begin{tabular}{|c|c|c|c|c|c|c|}
\hline \multirow[t]{2}{*}{ Television Channel } & \multicolumn{2}{|c|}{ Seven } & \multicolumn{2}{|l|}{ Nine } & \multicolumn{2}{|l|}{ Ten } \\
\hline & $\mathrm{SH}$ & ST & $\mathrm{SH}$ & ST & $\mathrm{SH}$ & ST \\
\hline High sugar group & 4.48 & 6.11 & 3.60 & 6.77 & 2.51 & 11.68 \\
\hline Breakfast cereals with added sugar & 0.55 & 0.22 & 0.00 & 0.66 & 0.66 & 0.44 \\
\hline Confectionary (sweets, biscuits, cakes) and snacks & 3.38 & 5.90 & 2.73 & 5.35 & 1.86 & 10.37 \\
\hline Flavoured milk drinks & 0.55 & 0.00 & 0.87 & 0.76 & 0.00 & 0.87 \\
\hline High acid group & 0.00 & 0.76 & 0.11 & 0.00 & 0.33 & 0.66 \\
\hline Sugar-free soft drinks and fruit juices & 0.00 & 0.76 & 0.11 & 0.00 & 0.33 & 0.66 \\
\hline High sugar and high acid group & 0.87 & 0.98 & 0.87 & 0.22 & 0.22 & 1.86 \\
\hline Sugar-sweetened drinks & 0.87 & 0.98 & 0.87 & 0.22 & 0.22 & 1.86 \\
\hline Low sugar and low acid group & 7.21 & 8.19 & 10.92 & 9.17 & 9.50 & 12.99 \\
\hline Dairy products & 0.66 & 0.76 & 0.00 & 0.87 & 0.00 & 1.09 \\
\hline Breakfast cereals with no added sugar & 0.22 & 0.33 & 0.76 & 0.44 & 0.33 & 1.20 \\
\hline Tea/coffee & 0.76 & 0.98 & 0.00 & 0.44 & 0.00 & 1.42 \\
\hline Convenience foods & 5.57 & 6.11 & 10.15 & 7.42 & 9.17 & 9.28 \\
\hline Total & 12.55 & 16.05 & 15.50 & 16.16 & 12.55 & 27.18 \\
\hline
\end{tabular}

${ }^{\circ}$ Chi-square $\left(X^{2}\right)=32.30, p<.001$ 
Table 4 Distribution (\%) of food advertisements according to the viewing times

\begin{tabular}{|c|c|c|c|c|c|c|c|c|c|c|c|c|}
\hline \multirow{2}{*}{$\begin{array}{l}\text { Television Channel } \\
\text { Time slot }\end{array}$} & \multicolumn{4}{|l|}{ Seven } & \multicolumn{4}{|l|}{ Nine } & \multicolumn{4}{|l|}{ Ten } \\
\hline & $\bar{C}$ & $\mathrm{O}$ & A & $\mathrm{O}^{*}$ & $\bar{C}$ & O & A & o & $\bar{C}$ & O & A & o \\
\hline High sugar group & 3.71 & 2.62 & 3.06 & 1.20 & 3.38 & 2.40 & 3.06 & 1.53 & 6.11 & 2.84 & 2.84 & 2.40 \\
\hline Breakfast cereals with added sugar & 0.11 & 0.33 & 0.33 & 0.00 & 0.11 & 0.11 & 0.00 & 0.44 & 0.76 & 0.11 & 0.00 & 0.22 \\
\hline Confectionery (sweets, biscuits, cakes) and snacks & 3.49 & 2.29 & 2.29 & 1.20 & 2.51 & 2.29 & 2.18 & 1.09 & 5.35 & 2.40 & 2.29 & 2.18 \\
\hline Flavoured milk drinks & 0.11 & 0.00 & 0.00 & 0.00 & 0.76 & 0.00 & 0.87 & 0.00 & 0.00 & 0.33 & 0.55 & 0.00 \\
\hline High acid group & 0.33 & 0.00 & 0.00 & 0.44 & 0.11 & 0.00 & 0.00 & 0.00 & 0.22 & 0.33 & 0.11 & 0.33 \\
\hline Sugar-free soft drinks and fruit juices & 0.33 & 0.00 & 0.00 & 0.44 & 0.11 & 0.00 & 0.00 & 0.00 & 0.22 & 0.33 & 0.11 & 0.33 \\
\hline High sugar and high acid group & 0.76 & 0.33 & 0.55 & 0.22 & 0.33 & 0.33 & 0.33 & 0.11 & 0.76 & 0.33 & 0.11 & 0.87 \\
\hline Soft drinks & 0.76 & 0.33 & 0.55 & 0.22 & 0.33 & 0.33 & 0.33 & 0.11 & 0.76 & 0.33 & 0.11 & 0.87 \\
\hline Low sugar and low acid group & 6.55 & 3.28 & 3.60 & 1.97 & 8.30 & 5.57 & 4.37 & 1.86 & 8.62 & 5.57 & 5.02 & 3.28 \\
\hline Dairy products & 0.55 & 0.55 & 0.33 & 0.00 & 0.66 & 0.11 & 0.11 & 0.00 & 0.11 & 0.33 & 0.33 & 0.33 \\
\hline Breakfast cereals with no added sugar & 0.22 & 0.11 & 0.22 & 0.00 & 0.87 & 0.22 & 0.11 & 0.00 & 0.55 & 0.44 & 0.00 & 0.55 \\
\hline Tea/coffee & 0.76 & 0.22 & 0.44 & 0.33 & 0.33 & 0.00 & 0.00 & 0.11 & 0.55 & 0.00 & 0.00 & 0.87 \\
\hline Convenience foods & 5.02 & 2.40 & 2.62 & 1.64 & 6.44 & 5.24 & 4.15 & 1.75 & 7.42 & 4.80 & 4.69 & 1.53 \\
\hline Total & 11.35 & 6.22 & 7.21 & 3.82 & 12.12 & 8.30 & 7.75 & 3.49 & 15.72 & 9.06 & 8.08 & 6.88 \\
\hline
\end{tabular}

$C$ Child viewing hours, $O$ Overlap viewing hours, $A$ Adult viewing hours, and $o$ Other viewing hours

${ }^{*}$ Chi-square $\left(X^{2}\right)=13.49, p<.001$ for other viewing hours

reported a decreasing trend for food and beverages decreased over the three-year period; from $26 \%$ in 2006 and $25 \%$ in 2007 to $15 \%$ in 2008 . It is also worthy to note that that the current Children's Television Standards [27] which cover television viewing times for children that is regulated by the Australian Communications and Media Authority came into action in 2014 which may also account for lower proportion of food advertisements in our study. However, a matter of concern is that the proportion of food and/or drink advertisements were the highest during the child-viewing period, during which it is highly likely that the adverts are viewed by children. Such exposure may have a strong influence on persuading children towards an unhealthy dietary lifestyle.

Although food and/or drink advertisements were low compared to the total adverts aired, the findings of this study highlighted that significant amount of the adverts promoted cariogenic food and/or drink products. Approximately, $40 \%$ of food and/or drink advertisements were related to dietary items that were high in either sugar or acid content, or both sugar and acid content. This percentage is less in comparison to an earlier Australian study by Kelly et al. which reported the proportion of food advertisements for high sugar or acid, or high sugar and acid products to be $61.3 \%$ [19]. The UK study by Rodd and Patel [24] reported this proportion to be over $55 \%$. These differences are possibly due to variations across countries, collecting a small amount of data over a short period of time, and collecting data during a more restricted period of the day. Nonetheless, food and/or drink advertisements of products containing high sugar and/or high acid pose a detrimental risk to oral health of children. Additionally, the consumption of high sugar foods is of concern for other public health issues such as obesity and diabetes [41-43]. This grants further reason for the government to implement stronger regulations on television advertising of unhealthy foods and/ or drinks aimed towards children.

The higher proportion of food and/or drink advertisements during school term is probably in compliance with recommended guidelines [27] prohibiting airing of unhealthy/non-core foods and/or drinks adverts during child-viewing time, especially during school holidays. Amongst all types of food and/or drink items, convenience food adverts predominated both during school term and holidays across all channels. Similarly, excessive advertising for foods and/or drinks potentially detrimental to oral health were also observed by other researchers [22-24, 44, 45], thereby concluding that children are being excessively persuaded towards high sugar products through children's and primetime television commercials. The present study has focused primarily on the role of sugar and acid content, frequent intake of which has been correlated with dental caries and tooth erosion.

A positive finding drawn from the present study is that the high proportion of food and/or drink advertisements were those promoting non-cariogenic dietary items. This finding is in contrast to findings of similar studies (i.e. children's television advertising) from different countries [46-48] and may reflect mandatory and self-regulatory advertising regulations.

Following the release of revised standards for television food advertising for children by the Australian Communications and Media Authority in 2009, there has been a 
decrease in the overall rate of food and/or drink advertisements (adverts per hour per channel) [27, 32]. All networks demonstrated a reduction in the proportion of food and/or drink advertisements aired during school holidays compared to school term. Children's Television Standards [27], Australian Food and Grocery Council selfregulatory initiatives [30, 31, 49], and the Commercial Television Industry Code of Practice [50] have likely been influential in reducing the overall number of food advertisements during child viewing hours; however, children are still exposed to a significant number of food and/or drink advertisements. The proportion of advertisements for non-core foods and/or drinks however, has remained almost steady since 2006 (50\% in 2006, $48 \%$ in 2007, $49 \%$ in 2008) [32].

In 2009, the Australian Food and Grocery Council promulgated a national self-regulatory initiative relating to responsible food marketing for children, encompassing food marketing on subscription services which was also adopted by several food companies [30]. Earlier Australian studies reported a higher rate of non-core food advertisements $[35,45]$ in comparison to the present study which might, in some way, be an outcome of the above mentioned responsible marketing policies adopted by food companies. However, such self-regulatory policies have limited government regulation and industry self-regulation [45]. Hence, government involvement is required to ensure stronger implementations to further control the promotion of unhealthy foods through television advertisements and ensure that children are persuaded towards healthier food choices-favourable to their oral health and overall growth and development.

The current study provides an insight into the extent of food advertising to children on three popular Australian channels with a particular focus on post-regulation advertising of foods potentially damaging to oral health. Some of the limitations of our study were limited number of channels that were recorded, a short recording period (i.e. 2 week days and one weekend day in school term and school holidays), and only considering the number of advertisements and not whether they were repeated, as some products may be advertised more often. Further, it is also difficult to prove that television advertising has a direct effect on oral health, given the multifactorial nature of dental caries and erosion. It is suggested that future studies be done with longer recording periods, and a broader variety of television channels for generalisability of the findings. Furthermore, other viewing modes such as Netflix, paid cable television, You Tube, and mobile phone applications, should be taken into account when evaluating children's exposure to food advertisements. Future studies should also account for oral hygiene products particularly fluoride, which have a protective effect towards child and adolescent oral health.

\section{Conclusion}

Although the overall proportion of food and/or drink advertisements aired on Sydney television is low, the advertisements containing high sugar and /or acid were broadcasted more during children's viewing times than other times and during school term compared to school holidays. Potentially, due to such adverts, there may be higher probability of parents being persuaded to procure unhealthy foods for their children, thereby posing a threat in terms of children's oral health alongside other health risks such as obesity and diabetes. This calls for stronger government involvement to restrain promotion of unhealthy food and/or drinks to children.

Abbreviations

(PG): Parental Guidance; (SH): School Holiday; (ST): School Term; (TV): Television

\section{Acknowledgements}

We would like to thank Dr. Jill Hnaituk, Deakin University and Dr. Debra Hector, Cancer Australia for their feedback on the earlier versions of the manuscript.

\section{Funding}

This study was supported by the Australian National Health and Medical Research Council Grants (1033213, 1069861, 1134075). The funding body did not play any roles in the design of the study, data collection, data analysis, interpretation of data, and in writing the manuscript.

Availability of data and materials

The advertisements were freely available on television.

\section{Authors' contributions}

$A A, C B, S C$ designed the study and undertook the writing of the drafts. $A A$, CB, SC, NM, JT undertook the data analysis. NM, JT, and SB assisted in providing critical feedback on the manuscript. All authors reviewed and approved the final version of the manuscript.

Ethics approval and consent to participate

This study did not require human research ethics approval as it did not involve study participants. Only analysis of publicly available leaflets was undertaken.

\section{Consent for publication}

Not Applicable.

\section{Competing interests}

AA is an Associate Editor for BMC Pediatrics but was not involved in handling the manuscript. All authors declare that they have no competing interests.

\section{Publisher's Note}

Springer Nature remains neutral with regard to jurisdictional claims in published maps and institutional affiliations.

\section{Author details}

${ }^{1}$ School of Science and Health, Western Sydney University, Campbelltown Campus, Locked Bag 1797, Penrith, NSW 2751, Australia. ${ }^{2}$ Translational Health Research Institute, Western Sydney University, Campbelltown Campus, Locked Bag 1797, Penrith, NSW 2751, Australia. ${ }^{3}$ Discipline of Child and Adolescent Health, Sydney Medical School, Faculty of Medicine and Health, The University of Sydney, Westmead, NSW 2145, Australia. ${ }^{4}$ Oral Health Services, Sydney Local Health District and Sydney Dental Hospital, NSW Health, Surry Hills, NSW 2010, Australia. ${ }^{5}$ Sydney Dental School, Faculty of Medicine and Health, The University of Sydney, Surry Hills, NSW 2010, Australia. 
Received: 28 June 2018 Accepted: 22 November 2018 Published online: 07 December 2018

\section{References}

1. Petersen PE. World Health Organization global policy for improvement of oral health-world health assembly 2007. Int Dent J. 2008:58:115-21.

2. Kassebaum N, Smith A, Bernabé E, Fleming T, Reynolds A, Vos T, et al. Global, regional, and national prevalence, incidence, and disabilityadjusted life years for oral conditions for 195 countries, 1990-2015: a systematic analysis for the global burden of diseases, injuries, and risk factors. J Dent Res. 2017;96:380-7.

3. Australian Research Centre for Population Oral Health. Dental caries trends in Australian school children. Aust Dent J. 2011;56:227-30. https://doi.org/10.1111/j.1834-7819.2011.01332.x.

4. Casamassimo PS, Thikkurissy S, Edelstein BL, Maiorini E. Beyond the dmft: the human and economic cost of early childhood caries. J Am Dent Assoc. 2009;140:650-7.

5. The Royal Australasian College of Physicians. Oral Health in Children and Young People - Position Statement. Sydney, Australia: The Royal Australasian College of Physicians; 2013. p. 1-21

6. Cameron A, Widmer RP. Handbook of pediatric dentistry. Edinburgh, UK: Elsevier; 2013.

7. Alm A, FÅHraeus C, Wendt L-K, Koch G, Andersson-GÄRe B, Birkhed D. Body adiposity status in teenagers and snacking habits in early childhood in relation to approximal caries at 15 years of age. Int J Paediatr Dent. 2008;18:189-96. https://doi.org/10.1111/j.1365-263X.2007.00906.X.

8. Vader AM, Walters ST, Harris TR, Hoelscher DM. Television viewing and snacking behaviors of fourth-and eighth-grade schoolchildren in Texas. Prev Chronic Dis. 2009:6:1-10.

9. Armfield JM, Spencer AJ, Roberts-Thomson KF, Plastow K. Water fluoridation and the association of sugar-sweetened beverage consumption and dental caries in Australian children. Am J Public Health. 2013;103:494-500.

10. Hardy LL, Bell J, Bauman A, Mihrshahi S. Association between adolescents' consumption of total and different types of sugar sweetened beverages with oral health impacts and weight status. Aust N Z J Public Health. 2018;42:22-6.

11. Story M, French S. Food Advertising and Marketing directed at children and adolescents in the US. Int J Behav Nutr Phys Act. 2004; 1(3). https://doi.org/10.1186/1479-5868-1-3.

12. Borzekowski DL, Robinson TN. The 30-second effect: an experiment revealing the impact of television commercials on food preferences of preschoolers. J Am Diet Assoc. 2001;101:42-6.

13. Cairns $G$, Angus $K$, Hastings $G$. The extent, nature and effects of food promotion to children: a review of the evidence to December 2008. Geneva: World Health Organization; 2009.

14. Livingstone $\mathrm{S}$, Helsper E. Advertising foods to children: understanding promotion in the context of Children's daily lives. London: Dept of media and communications, London School of Economics and Political Science; 2004.

15. Committee on Food Marketing and the Diets of Children and Youth Institute of Medicine. Food marketing to children and youth: threat or opportunity? McGinnis JM, Gootman JA, Kraak VI, editors. Washington DC: National Academies Press; 2006.

16. Andreyeva T, Kelly IR, Harris JL. Exposure to food advertising on television: associations with children's fast food and soft drink consumption and obesity. Econ Hum Biol. 2011;9:221-33.

17. Halford JC, Boyland EJ, Hughes GM, Stacey L, McKean S, Dovey TM. Beyondbrand effect of television food advertisements on food choice in children: the effects of weight status. Public Health Nutr. 2008;11:897-904.

18. Kelly B, Freeman B, King L, Chapman K, Baur LA, Gill T. Television advertising, not viewing, is associated with negative dietary patterns in children. Pediatr Obes. 2016;11:158-60.

19. Kelly B, Hattersley L, King L, Flood V. Persuasive food marketing to children: use of cartoons and competitions in Australian commercial television advertisements. Health Promot Int. 2008;23:337-44. https://doi.org/10.1093/heapro/dan023.

20. Hebden L, King L, Kelly B. Art of persuasion: an analysis of techniques used to market foods to children. J Paediatr Child Health. 2011:47:776-82.

21. Sukumaran A, Diwakar MP, Shastry SM. A content analysis of advertisements related to oral health in children's Tamil television channels-a preliminary report. Int J Paediatr Dent. 2012;22:232-8.
22. Al-Mazyad M, Flannigan N, Burnside G, Higham S, Boyland E. Food advertisements on UK television popular with children: a content analysis in relation to dental health. Br Dent J. 2017;222:171.

23. Morgan M, Fairchild R, Phillips A, Stewart K, Hunter L. A content analysis of children's television advertising: focus on food and oral health. Public Health Nutr. 2009;12:748-55. https://doi.org/10.1017/\$1368980008003169.

24. Rodd HD, Patel V. Content analysis of children's television advertising in relation to dental health. Br Dent J. 2005;199:710. https://doi.org/10.1038/s..bdj.4812967.

25. Azar FP, Mamizadeh M, Nikniaz Z, Ghojazadeh M, Hajebrahimi S, Abdolahi HM. Content analysis of advertisements related to oral health in children: a systematic review and meta-analysis. Public Health. 2018; 156:109-16.

26. Movahhed T, Seifi S, Rashed Mohassel A, Dorri M, Mohammadzadeh Z. Content analysis of Islamic Republic of Iran television food advertising related to oral health: appeals and performance methods. J Res Health Sci. 2014;14:205-9.

27. Australian Communications and Media Authority. Children's Television Standards. Canberra: Australian Communications and Media Authority; 2014.

28. Roberts M, Pettigrew S, Chapman K, Miller C, Quester P. Compliance with children's television food advertising regulations in Australia. BMC Public Health. 2012;12:846.

29. Roberts M, Pettigrew S, Chapman K, Quester P, Miller C. Children's exposure to food advertising: an analysis of the effectiveness of self-regulatory codes in Australia. Nutr Diet. 2014;71:35-40. https://doi.org/10.1111/1747-0080.12040.

30. Australian Food and Grocery Council. Responsible Children's marketing initiative. Canberra: Australian food and grocery council; 2009.

31. Australian Food and Grocery Council. Quick service restaurant initiative for responsible advertising and marketing to children. Canberra, Australia: Australian Food and Grocery Council; 2014. p. 1-10.

32. Kelly B, Chapman K, King L, Hebden L. Trends in food advertising to children on free-to-air television in Australia. Aust N Z J Public Health. 2011; 35:131-4. https://doi.org/10.1111/j.1753-6405.2011.00612.x.

33. Neville $L$, Thomas M, Bauman A. Food advertising on Australian television: the extent of children's exposure. Health Promot Int. 2005;20:105-12. https://doi.org/10.1093/heapro/dah601

34. Kelly B, Smith B, King L, Flood V, Bauman A. Television food advertising to children: the extent and nature of exposure. Public Health Nutr. 2007:10:1234-40. https://doi.org/10.1017/S1368980007687126.

35. Hebden L, King L, Chau J, Kelly B. Food advertising on children's popular subscription television channels in Australia. Aust N Z J Public Health. 2011; 35:127-30. https://doi.org/10.1111/j.1753-6405.2011.00610.x.

36. Dixon HG, Scully ML, Wakefield MA, White VM, Crawford DA. The effects of television advertisements for junk food versus nutritious food on children's food attitudes and preferences. Soc Sci Med. 2007;65:1311-23. https:/doi.org/10.1016/jsocscimed.2007.05.011.

37. Australian Bureau of Statistics. Australian health survey: physical activity, 2011-12. Canberra: Australian bureau of Statistics; 2015.

38. Zuppa JA, Morton H, Mehta KP. Television food advertising: counterproductive to children's health? A content analysis using the Australian guide to healthy eating. Nutr Diet. 2003;60:78-84.

39. Hebden LA, King L, Grunseit A, Kelly B, Chapman K Advertising of fast food to children on Australian television: the impact of industry self-regulation. Med J Aust. 2011;195:20-4.

40. ninemsn Pty Ltd. Sydney TV Guide 2013 [January, 2013]. Available from: http://www.yourtv.com.au/guide/tonight/.

41. Hooley M, Skouteris H, Millar L. The relationship between childhood weight, dental caries and eating practices in children aged 4-8 years in Australia, 2004-2008. Pediatric Obesity. 2012:7:461-70. https://doi.org/10.1111/j.2047-6310.2012.00072x.x.

42. DeBoer MD, Scharf RJ, Demmer RT. Sugar-sweetened beverages and weight gain in 2-to 5-year-old children. Pediatrics. 2013;132:413-20.

43. Bray GA, Popkin BM. Dietary sugar and body weight: have we reached a crisis in the epidemic of obesity and diabetes?: health be damned! Pour on the sugar. Diabetes Care. 2014:37:950-6

44. Chestnutt IG, Ashraf FJ. Television advertising of foodstuffs potentially detrimental to oral health--a content analysis and comparison of children's and primetime broadcasts. Community Dent Health. 2002;19:86-9.

45. Kelly B, Halford J, Boyland E, Chapman K, Bautista-Castaño I, Berg C, et al. Television food advertising to children: a global perspective. Am J Public Health. 2010;100:1730-6.

46. Hammond KM, Wyllie A, Casswell S. The extent and nature of televised food advertising to New Zealand children and adolescents. Aust N Z J Public Health. 1999:23:49-55. https://doi.org/10.1111/j.1467-842X.1999.tb01204.X.

47. Li D, Wang T, Cheng Y, Zhang M, Yang X, Zhu Z, et al. The extent and nature of television food advertising to children in Xi'an, China. BMC Public Health. 2016:16: 770. https:/doi.org/10.1186/s12889-016-3468-0. 
48. Amini M, Omidvar N, Yeatman H, Shariat-Jafari S, Eslami-Amirabadi M, Zahedirad M. Content analysis of food advertising in Iranian Children's television programs. Int J Prev Med. 2014;5:1337-42.

49. King L, Hebden L, Grunseit A, Kelly B, Chapman K, Venugopal K. Industry self regulation of television food advertising: responsible or responsive? Int $J$ Pediatr Obes. 2011;6:e390-e8. https://doi.org/10.3109/17477166.2010.517313.

50. Australian Communications and Media Authority. Commercial Television Industry Code of Practice. Canberra: Australian Communications and Media Authority; 2015. p. 1-38.

Ready to submit your research? Choose BMC and benefit from:

- fast, convenient online submission

- thorough peer review by experienced researchers in your field

- rapid publication on acceptance

- support for research data, including large and complex data types

- gold Open Access which fosters wider collaboration and increased citations

- maximum visibility for your research: over $100 \mathrm{M}$ website views per year

At BMC, research is always in progress.

Learn more biomedcentral.com/submissions 